\title{
Erratum to: Peter Bela Fodor, M.D., F.A.C.S., Medical Editor, Elizabeth Sadati Bernard, Editorial Consultant, Bill Winn, B.S., M.S., F.A.M.I., Medical Illustrator, and Rex M. Oppenheimer, Coordinating Author: Be Your Best: A Comprehensive Guide to Aesthetic Plastic Surgery
}

Insight International Press, LLC, Austin, TX, 1st edn., 288 pp

\section{Thomas M. Biggs}

Published online: 17 September 2010

(C) Springer Science+Business Media, LLC and International Society of Aesthetic Plastic Surgery 2010

Erratum to: Aesth Plast Surg

DOI 10.1007/s00266-010-9514-x

The authorship of this book was incorrectly stated in the book review by T. Biggs. The authors are Peter Bela Fodor,
M.D., F.A.C.S., Medical Editor, Elizabeth Sadati Bernard, Editorial Consultant, Bill Winn, B.S., M.S., F.A.M.I., Medical Illustrator, and Rex M. Oppenheimer, Coordinating Author.

The online version of the original article can be found under doi:10.1007/s00266-010-9514-x.

T. M. Biggs $(\bowtie)$

1315 St. Joseph Parkway, Suite 900, Houston, TX 77002, USA

e-mail: tbiggsmd@aol.com 